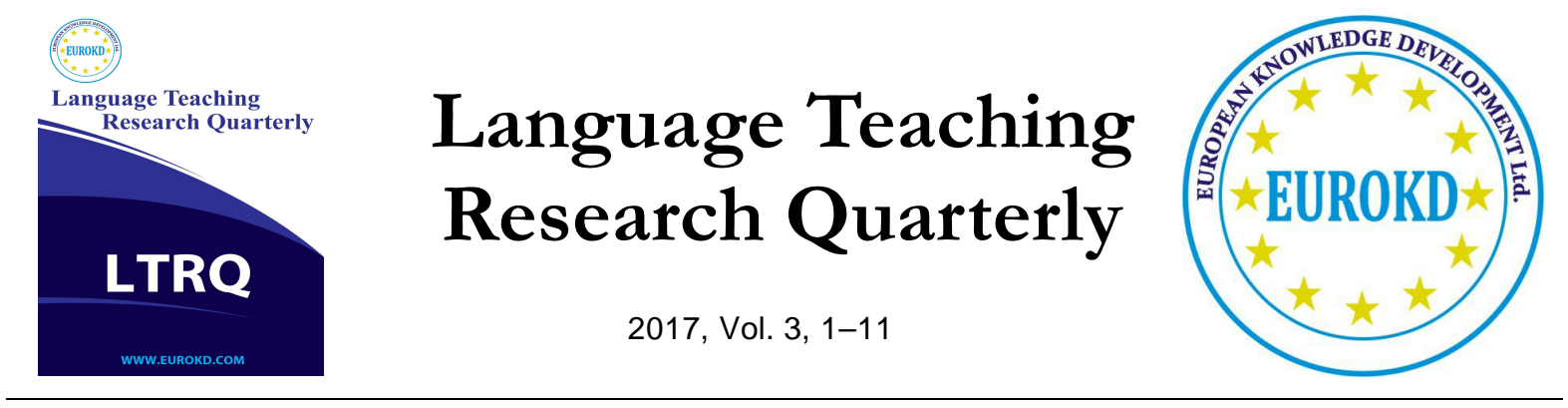

\title{
Introducing New Target Vocabulary through the Interactive Approach
}

\author{
T.A. Ihumnova \\ Polotsk State University, Belarus \\ Received 29 March 2017 Accepted 12 July 2017
}

\begin{abstract}
Trends in teaching and learning of English as Additional Language (EAL) have undergone a great transformation during the last century. At the same time, one of the most difficult aspects of learning English is still the retention of vocabulary. Traditional methodologies have often been the breeding ground of ineffective learning environments in which learners are reluctant to participate and do not feel being motivated. This paper attempts to highlight the efficiency of teaching vocabulary through playing card games. Students in both treatments read stories containing novel target words. Group 1 was asked to look up the words in a dictionary and to memorize them. Group 2 was to write out 12 difficult words for playing games. The next day the roles of the groups was changed. Both groups showed $47 \%$ and $53 \%$ gains for vocabulary perception respectively. The analysis on the spelling correction was carried out as well. Another study was conducted with two teams, given a group of new words, where only one group was asked to compose a story. Results extend previous studies' results on general benefits of novel word exposure in story contexts, and specific benefits for spelling and pronunciation practice in learning new words. It was concluded that through interactive approach students outscored more than while using traditional method of teaching English.
\end{abstract}

Keywords: Vocabulary, Card Games, New Words, Memorize

\section{Introduction}

Vocabulary learning has always been a major concern for those who learn English as a foreign language. Vocabulary bears the burden of linking speaking, listening, reading and writing together. In order to communicate well in a foreign language, students should acquire a sufficient number of words in a foreign language and should know how to compose sentences. Imperfect grammar and pronunciation do not prevent communication and enjoyment of the language. You 
will be definitely understood. But lack of vocabulary can really make feel an odd one out. Even though students realize the importance of vocabulary when learning language, most of them learn vocabulary unwillingly. That happens because they find the teacher's explanation for meaning or definition, pronunciation, spelling and grammatical functions boring. Students may as well guess the meaning of a word in its written or spoken form and think that they already "learnt the word", but they may not be able to use that word properly in different contexts or pronounce it correctly.

Traditional methodologies have often been counted as ineffective learning environments in which learners hardly ever take an active voluntary part. What advantages do the new trends in theory and pedagogy offer to ESL (English as a second language) teachers to avoid what is coined as the "inert knowledge problem" (Freeman, 2010)? To answer this question systematically, as Klepper (2003) suggested, to form a basis for researching the effectiveness of games used in vocabulary instruction, it would be useful to review previous researches done in related area.

Most academic reviews start from an assumption that games, together with other aspects of learning are beneficial. However, we decided to single out the method of learning new vocabulary through vocabulary card games to study that separately from other known methods of vocabulary acquisition. Does the use of word card games truly have positive impact when learning new vocabulary? Does the implication of vocabulary cards make students feel more comfortable and interested in learning new words? Are there any problems that occur during the process of teaching through vocabulary cards?

It should be stated that there are relatively few academic opinions on this specifically focused matter. It was decided to start our research by applying games in our own classes and in other teachers' classes, comparing the results and interviewing both teachers and learners so as to elicit students' reactions, their feelings and ideas about the usefulness of vocabulary card games in vocabulary learning.

Games to great extent are considered of some importance just for their one element that is fun. But in fact, as Angkana Deesri (2002) stated, games can provide EFL (English as a Foreign Language) and ESL student's more than that. He gave the definition to games as a form of play governed by rules. Games are not just a diversion, a break from routine activities, but a way of getting the learner to use the language in the course of the game. Games are another useful strategy to promote student's language proficiency. Students seem to learn new vocabulary more quickly and retain it better when it is applied in a relaxed and comfortable environment such as while playing ESL games. Further on the topic, Donmus (2010) was convinced that the value of educational games had increased in language education since they helped to make language education entertaining.

Learning vocabulary is definitely not an easy task to do, so much effort is required to understand, memorize and learn how to use the target words. Games help and encourage learners to learn target language quicker and more easily. Using games allows teachers to create contexts in which the target words reveal their meaning, become close to life. Games bring fun into 
classroom atmosphere, which, in its turn, help students learn and memorize new words more quickly. In other words, learning, which is based on games, can benefit a lot by creative a meaningful context in language learning process. While learning and practicing new vocabulary through games, students have the possibility to speak a foreign language in a non-stressful way. Uberman (1998) also states the helpful role of games in vocabulary teaching after quoting and analyzing different opinions of experts. From her own teaching experiences, she observed the enthusiasm of her students in learning through games. She considers games a way to help students not only enjoy and entertain with the language they learn, but also practice it incidentally. Newton (2001) affirms to this approach as a way that can enable learners to manage their vocabulary meaning and develop their communicative skills at the same time. With the use of games, the teacher can create various contexts in which students have to use the language to communicate, exchange information and express their own opinions (Wright, Betteridge, and Buckby, 1984). Moreover, according to Huang (1997), learning through games could encourage the operation of certain psychological and intellectual factors which could facilitate communication heightened self-esteem, motivation and spontaneity, reinforcing learning, improving intonation and building confidence. Some experts have also figured out characteristics of games that make vocabulary learning more effectively. Lee (2011) lists several main advantages when games are used in the classroom, including a welcome break from the usual routine of the language class, motivating and challenging effort of learning, and language practice in the various skills. Ersoz (2000) believes that games are highly appreciated thanks to their amusement and interest.

Sir Christopher Ball (as cited in Satish, 2011) stated that "learning is a natural instinct, and teaching is an art that can be mastered. I like to learn in $7 \mathrm{C}$ environments. The seven Cs are choice, challenge, clarity, confidence, comfort and two more I have not identified yet.” For us the two $\mathrm{C}$ factors that can be added to these $5 \mathrm{Cs}$ are co-operation and card games. The process of learning with the help of card games is beneficial for all the participants, as no one is left out and at the same time everyone is focused on the successful results of the team as a whole. There is one more obvious thing to be mentioned here. It is the group work as a component of strong motivation. Students are more likely to express themselves working in teams rather than answering the teacher in person. Being provided with a challenge, students feel more freedom to cooperate with each other in order to solve the challenge. They discuss various strategies more freely, communicating their ideas more open, and are not afraid of making mistakes. It is reasonable to give learners more freedom. Freedom to make decisions with little teacher intervention. Freedom here should be properly defined and understood as it can actually have various meanings. What we bear in mind is freedom from teacher's explanations, intrusive correction and absolute control. Students should have a feeling of self-made decisions, selfcontrol and their personal motivation to be involved in a discussion that takes place in the lessons. It obviously does not mean that teachers are of no importance at all. They do have a role. They are guides, masterminds, motivators. The learner should be free to choose content to learn from, to choose words and phrases to learn. 
The increasing importance of interactive approach in the classroom has been gaining its territory rapidly. Activity-based teaching and learning stresses the positive effects on how quickly and with much less efforts learners acquire new material. Research on learning and memory (Sprenger, 1999), on language acquisition and language learning (Cameron, 2001), and on the functions of the brain (Genesse, 2000) shows that English language learners are not passive recipients of learning. Thus, all teaching - even direct teaching - must be planned so that learners play active role as they learn.

Rivers (1987) came to a conclusion that, it is through the interactive approach, with its emphasis on playful group activities, that a simple point or group of related points can be revived and, above all, personalized. Whether we are speaking or writing we comprehend and express the meaning constantly to interact in real life communication. Language learning should be fun, and can be. It almost has to be, if a person is going to succeed to learn another language. In fact, the overwhelming goal of language teaching has to be to make the learning of the language meaningful and enjoyable. Yet the place where the vocabulary cards and their efficiency on vocabulary acquisition is studied attracted a noticeable lack of attention.

For learning vocabulary, one needs to be able to remember long term. Information first is held in short-term memory and by lack of attention, it is quickly lost. In order for the information in the short term to be retained, enough rehearsal and elaboration is needed. The more that the knowledge is rehearsed in the memory the more likely it is to be retained in long term memory (Klepper, 2003). It is important to keep student attention, in order to increase their ability to retain words. One way to keep students' attention as the scholar suggested is "emotion". When an educator creates emotion, such as in a game format, then the students' attention is most likely to remain with the material studied.

To use games in English class effectively, not just for mere fun of it, several factors are to be considered. One is choosing appropriate games to a group of learners which depend on number of students in class, level of language proficiency, students' age, class specialization, topics of discussion. To add more, teachers should thoroughly consider how to implement games in different classes. This study aimed to guide teachers and language learners to a better understanding of vocabulary learning through educational card games, its place and efficiency in the complex system of studying a foreign language.

\section{Methods}

In the present study, we conducted an experiment especially thought over to investigate the role of vocabulary cards in learning difficult (unknown) words through game-based learning activities. The present study was implemented on the students of Polotsk State University in 2011. The participants were 20 first-year university students, who were selected to take part in this study. Subjects were 2 groups of students who were given tasks for building up vocabulary. The two chosen groups of students were control and experimental groups. Within the process of studying the groups were changed to get objective reflection and reliable results. The age of the 
participants in both groups was seventeen. The pedagogical features that were taken into consideration are as follows:

- Selected topics matching students' level of understanding, knowledge of the world and interests for enabling more fruitful interaction.

- Authentic material was used as the texts for the activity.

- The students were divided into groups and further into teams considering their previously shown results in study. Each team included students of high academic achievements, learning progress and results as well as low ones.

- Group work provided opportunities for the students to improve their proficiency in English language by interacting with other group members more freely.

- Comprehension and discussion of ideas as well as fluency were viewed by us as more important than accuracy in speaking so that to increase students' participation and involvement. However, accuracy was checked and the mistakes were corrected and discussed later.

- The teachers monitored the process of the activity by providing students with the necessary scaffolding. Thus, the principles and assumptions of Communicative Language Teaching were revealed.

- Seating arrangement: each group of students was placed in a different room. The students in the experimental group were in their turn divided into 2 teams for playing vocabulary card games. The teams were seated on the sides for better communication opportunities.

- The study was conducted in the first half of the day, when the students were not overwhelmed with learning.

-At the time of discussion and preparation, the teacher moved around the classroom and facilitated each team in turns.

- The students expressed their views and gave feedback on the whole process and the way they had coped with certain difficulties.

The study took place in the students' study period. The control group was allowed to use dictionaries between pre-test and after-test periods; however, the experimental group was taught by vocabulary card games. For both groups we made use of self-prepared vocabulary test as the means of conducting the study. Both the qualitative and the quantitative approaches were applied.

English learners were randomly assigned to reading some stores delivered by teachers. The students in both treatments read stories containing novel target words. In one group students were asked to look up the words in a dictionary and to memorize them. In the other group the students were divided into 2 teams. Each team was told to write out 12 difficult words when they first appeared in the stories. Each team worked out a list of words and wrote those words on a card. So, on the front of the card were 12 words in English. The back of the card contained the translation of the words. Students played in teams. The teams exchanged the cards and placed them face up on the desk. All players studied the cards for 2 minutes. Then the cards were handed in to the teacher, who asked students for translation of the target words, definitions, synonyms and antonyms, sentences, illustrating different meanings of the words discussed. A lot of students 
were really quick at answering and their answers were accurate. Others sometimes could not give an answer, but, what is important, they could learn from their classmates' answers.

We continued the study by making the task with vocabulary cards more complicated and effort demanding. At that time the students were asked to write out 12 words each. All in all, we had 10 vocabulary cards with 12 words written out on every card. Each team first studied 5 cards of its members. The cards were then turned face down. One player chose a card at random and gave to each target word a definition or a synonym, or a sentence with the word missing in order to illustrate its meaning. Cards were turned face up as they were identified. Further on the teams exchanged their vocabulary cards with each other and repeated the game with 5 cards of the opposite team. The play continued until all words were identified. The team with the most cards showing at the end of the game won.

The next day the work was continued with the same teams, but on the basis of another story and the roles of the groups were changed.

The analysis on the spelling correction was carried out as well. The students in teams worked out a list of new words while reading a text for the first time and wrote those words on a card. Then, the vocabulary cards were exchanged first among the students of one and the same team, later among the students of the opposite team. The students were asked to stand beside their desks - each row formed a team. The first player from each row received a piece of chalk or a marker to write with. When the teacher named a word from a card, the students were to run to the board to write it. The teams' representatives gave turn to the next students in lines and took their places at the end of the rows. The team with more words spelled correctly won. From time to time, the students were given a synonym or an antonym to reveal the meaning of the word. The students had discussed the meaning for some time before the representative ran to write it. It is necessary to highlight the importance of providing students with the possibility to discuss the words, prior to writing them on the board. The discussion was conducted in English, which, of course, is beneficial in its own implication. So, we state the opportunity to combine listening comprehension with speaking and writing as an advantage of using this type of vocabulary card games. Three days later the students were given dictation on the targeted words.

Another study was conducted on the basis of the following game. Students played in teams. Word cards were prepared by students for words they fail to remember or find difficult to memorize. In the present study, the basic approach to target words was concluded from Wilkinson and Houston-Price (2013), who examined the learning of "difficult" vocabulary words as unlikely to be known by students through multiple-story contexts. Words were specifically selected to be "highly unlikely to be known “. Each team was assigned a list of 20 words that they were asked to use in a story. The words might be used in any order, but preferably had to be all used in the course of the story, which the students composed on their own. A time limit of 15 minutes was imposed. The composed stories were read aloud and the number of correctly used words was counted. The participants were not allowed to reproduce any sentence from the original texts verbatim except for some technical words. We took into consideration the context the words were used in, the derivative forms of the words. If a word was named several 
times within a story, it was counted as one word. A week later the words were checked in written way and orally. This very game gave the students the opportunity not only to learn the meaning of the unknown words from the context, as the words were written out of the given text, but to compose a new context, revealing different shades in meaning the words have.

\section{Obtained results}

All of the learners in our groups expressed their wish to learn vocabulary effectively in more interesting ways rather than through the traditional ways that they knew. What we wanted to know was whether vocabulary card games worked or not. Most of the learners (18 out of 20) expressed their wish to participate in through-games learning and they did their best to bring the victory to their teams. It should be noticed that for some students it was even more important to be a member of the team-winner, rather than to be winners themselves. It was especially true about shy students, for whom group work is ideal to express themselves. The students collaborated quite actively in games that required group work, even the quiet students. They said that they liked the relaxed atmosphere, despite the competitiveness that games brought to the classroom. That was because the students had a chance to use their imagination and creativity during activities like games in the classroom; therefore, they were motivated to learn (Domke, 1991).

It was important to get to know if our students made any progress in learning through playing vocabulary cards. For the first game, the one where the students in teams were asked to work out a card with 12 words, learn the words and then exchange the cards, the survey was conducted on the basis of self-composed vocabulary comprehension test. All students were assessed on their vocabulary acquisition. Both groups showed $47 \%$ and $53 \%$ gains for vocabulary perception respectively, when being checked 3 days later on the new words, which they have learnt with the help of the vocabulary cards, as opposed to traditional way of learning. It was proved, pronouncing a word several times enables the students to remember it longer and identify it more readily when they hear or see it.

Tables 1 and 2 depict the number of words gained by control and experimental groups within the process of vocabulary acquisition.

Table 1 . The number of words the students remembered using dictionaries only (control group)

\begin{tabular}{l|l|l|l|l|l|l|l|l|l|l|l|l|l|l|l|l|l|l|l|l}
\hline Team 1 & \multicolumn{10}{c|}{ Team 2 } \\
\hline student & 1 & 2 & 3 & 4 & 5 & 6 & 7 & 8 & 9 & 10 & 1 & 2 & 3 & 4 & 5 & 6 & 7 & 8 & 9 & 10 \\
\hline $\begin{array}{l}\text { words } \\
\text { remembered }\end{array}$ & 4 & 7 & 5 & 8 & 6 & 8 & 3 & 7 & 12 & 5 & 9 & 8 & 7 & 6 & 7 & 6 & 4 & 7 & 6 & 4 \\
\hline
\end{tabular}

Table 2. The number of words the students remembered after playing vocabulary card games (experimental group).

\begin{tabular}{l|l|l|l|l|l|l|l|l|l|l|l|l|l|l|l|l|l|l|l|l}
\hline \multicolumn{10}{c}{ Team 1} \\
\hline student & 1 & 2 & 3 & 4 & 5 & 6 & 7 & 8 & 9 & 10 & 1 & 2 & 3 & 4 & 5 & 6 & 7 & 8 & 9 & 10 \\
\hline $\begin{array}{l}\text { words re- } \\
\text { membered }\end{array}$ & 7 & 9 & 8 & 10 & 9 & 12 & 7 & 12 & 12 & 9 & 10 & 12 & 11 & 8 & 11 & 9 & 9 & 12 & 8 & 8 \\
\hline
\end{tabular}


As seen from the tables provided, the students of both groups showed gains for vocabulary perception after being treated in interactive environments with the help of vocabulary card games.

As for the study based on story composition, the students of both teams remembered 89\% and $86 \%$ of the given words respectively. The results we gained extend previous studies' results on specified benefits of novel word exposure in story contexts. We specified the advantages of using vocabulary card games in spelling and pronunciation practice while learning new words as well. The difference is that the words were not taken from context for further perception and comprehension only, but were used to compose new stories on their basis, which in its turn, enabled the language learners to begin to build emotional and sensory contexts around new vocabulary. Instead of just studying new words separately, without being stuck to any context, new vocabulary could be memorized quicker because it is linked to characters, personal emotions places and relationships, just like in real life. The ability to use words in various contexts and to "extend" their meaning separates very advanced learners of a language (C2 level) from intermediate or advanced ones (B1 - C1 level). The aim of this vocabulary game was not just to remember the words, but to know how to use them in context. It should be noticed, that the spelling benefits observed for the experimental group might be considered in light of targeted words connection with personal experience. The students of the experimental group exhibited an advantage over the control group by writing the words with fewer mistakes and with more confidence.

Through our post-game survey of the groups, all students confirmed that their classmates helped them to remember words for the games. 16 out of 20 students said they could learn lots of new words from their classmates. Also, 18 questioned students said that games are one of the most effective ways of learning vocabulary. Most students declared that it became much easier for them to use new, recently learnt vocabulary since they started to actively participate in vocabulary card games activities.

As practice showed, it is much more interesting and useful for students to learn through vocabulary games. There is a great variety of them for students in their attempts to build up vocabulary. In this exploratory study we examined the value of using vocabulary cards when teaching spelling and pronunciation of word forms while introducing new and difficult vocabulary words. The findings of this study showed that freedom from being totally controlled by the teacher, ability to work in small groups, extrinsic motivation and high interaction level are the dominating factors of successful second language learning.

While the activities described above in our study are not the final solution to the problem of vocabulary acquisition and retention, they have proved to be challenging for students and easy to use for teachers. Being personally involved in the process of choosing the vocabulary and learning it in informal, more interactive way, as well as students' self-satisfaction with the pace they acquire new words encourage students to take a more active approach to vocabulary development and keep on learning with much greater concernment. They have the added advantages of being self-paced and regulated. The game is worth the candle. 


\section{Unanticipated problems}

At first, we hypothesized that if vocabulary learning was less emotionally stressful when accompanied with activities like games, students would not face any difficulties. However, basing on observations of other teachers' classes and interviews, on our personal experience we cannot but admit that sometimes games create problems for both students and teachers. Games can be sophisticated if the teacher does not explain the tasks and roles of students clearly in playing games. Students may get confused and the pleasure of relaxed atmosphere will be lost. All explanations that teachers give concerning the rules of games should be simple, clear and understandable for students.

One more fact that should not be ignored is that the teacher ought to choose the texts for further playing card games very carefully. Vocabulary card games can only be a meaningful, effective and educational part of the whole complex learning process, if they are within the framework of educational programs, lesson plans and topics of discussion. The role of context, which provides the lexical environment, is one of the crucial factors in vocabulary acquisition. Only then the vocabulary cards can become a significant part of already known learning strategies and technics, but not just a mere means of amusement with slightly noticeable results.

Another issue related to using vocabulary card games for language learning is the fact that students usually tend to speak their mother tongue to negotiate rather than the language they are learning. It goes without saying that it is one more extra point the teacher should take notice of when introducing communicative skills in a foreign language learning. For groups of students who speak the same language, it is unavoidable to prefer using their first language to English. In competitive environment it is time that matters. To save time students use the language they speak more. Even advanced students in our classes still discussed different points with each other in their own language from time to time. Though, we try to impose English as the only language spoken in the classroom, especially for the university students, who, after school graduating have quite a good command of English.

\section{Conclusion}

Learning vocabulary has been considered by students a boring subject for a long time. Vocabulary acquisition is considered to be a traditional way of learning vocabulary by mere copying and remembering new words. At the same time, games have been seen as a time-filling activity for most teachers. It is believed that games are just for fun and they have very little effect in teaching and learning. However, our research reveals that games not only do help learners study in a more relaxed atmosphere, full of fun and friendly competition, but presents obvious advantages in students' control results. Students are eager to try such new methods of learning vocabulary as card games, which showed to be efficient and personally oriented at the same time. This, in its turn, help learners memorize and retain new words more easily. Students themselves are ready to participate in such activities, because games keep them interested and involved. Students are concentrated on the process itself, being active, open and inquisitive. These are 
crucial markers of critical thinking disposition characteristics in second language learning. The role of games in teaching and learning vocabulary cannot be denied.

However, in order to achieve the most from vocabulary games, it is of ultimate importance that the teacher should choose games with great accuracy. Such things as the number of students, their proficiency level, relations among the students in the class, the number of hyper- and low - activity students, time you have at your disposal, cultural context, the classroom settings, topic of discussion are factors that should be taken into account. The results of this research suggest that vocabulary card games can be used for the useful practice and review of language lessons, thus leading towards the primary goal of learning: improving learners' communicative competence.

Learning will take place best if the learner touches upon the topics of personal importance, experiences pleasure and reward. Pleasure can come from activities where the challenge is meaningful to the learner and appropriate to his or her skills, creating a sense of achievement. Enjoyment can also come from hearing pleasant sounds (group mates' uplifting phrases). Pleasure increases the production of dopamine in the brain, which in turn improves performance and memory. The study of the language becomes its own reward. One would not doubt that repeating is effective. Card games are a good way to fulfill this goal.

It was concluded that through using vocabulary card games students outscored more than while using traditional method of teaching English. It is recommended that prospective language teachers should use interactive approach in teaching a foreign language by developing intrinsic motivation of students. The teachers must be encouraged to apply the use of vocabulary card games in classroom situations for teaching/learning the English language as a helpful device in developing skills of language proficiency.

\section{References}

Brown, D. H. (2001). Teaching by Principles: An Interactive Approach to Language Pedagogy, 2nd ed. New York: Longman.

Cameron, L. (2001). Teaching languages to young learners. New York, NY: Cambridge University Press.

Deesri, A. (2002). Games in the ISL and EFL class. The Internet TESL Journal. Vol. VIII, No. 9. Retrieved from http://iteslj.org/Techniques/Deesri-Games.

Donmus, V. (2010). The use of social networks in educational computer-game based foreign language learning. Social and behavior sciences, 9, 1497-1503.

Ehri, L. C., \& Rosenthal, J. (2007). Spellings of words: A neglected facilitator of vocabulary learning. Journal of Literacy Research, 39, 389-409.

Ersoz, A. (2000). Six games for the EFL/ESL classroom. The Internet TESL Journal, Vol. VI, No. 6, June 2000. Retreived from http://iteslj.org/Lessons/Ersoz-Games.

Freeman, D., Freeman, Y., Garcia, A.C., and Silva, C. (2010). On your way to English, K-5. Austin, TX: Rigby/Houghton Mifflin Harcourt. 
Genesse, F. (2000). Brain research: Implications for second language learning. University of California, Santa Cruz: Center for Research on Education, Diversity and Excellence Occasional Reports. (ERIC Document Reproduction Service Paper 00 12.) Retrieved from http://pegasus.cc.ucf.edu/ -gurney/Brainlearning.doc

Huang, S.J. (1997). The preliminary study of the indirect use of computer simulation in EFL teaching. Paper presented at the first international conference of CALL, Naval Academy, Taiwan.

Kaufmann, S. (2009). The linguist on language. Published in Canada by Steve Kaufmann.

Klepper, S. (2003). The Geography of Organizational Knowledge. Great Britain: MPG Books Ltd, Bodmin, Cornwall.

Lee, J. (2011). Size matters: Early vocabulary as a predictor of language and literacy competence. Applied Psycholinguistics, 32, 69-92.

Newton, J. (2001). Options for vocabulary learning through communication tasks. ELT Journal, 55(1), 30-37.

Rivers, W. Language Policy, Planning and Practice in Interactive Language Teaching. Cambridge: Cambridge University Press, 1987, 65.

Satish, T. (2011). Research in the Language Laboratory: Efficacy of Language Laboratory on Teaching Vocabulary Building in English. International Journal of Education and Allied Sciences. July-December 2011, Volume 3, No. 2, 83-90.

Sprenger, M. (1999). Learning and memory: The brain in action. Alexandria, VA: ASCD.

Uberman, A. (1998). The use of games: For vocabulary presentation and revision. English teaching forum, 36 (1), 20.

Wilkinson, K. S., \& Houston-Price, C. (2013). Once upon a time, there was a pulchritudinous princess...: The role of word definitions and multiple story contexts in children's learning of difficult vocabulary. Applied Psycholinguistics, 34, 591-613.

Wright, A., Betteridge, D., and Buckby, M. (1984). Games for Language Learning. Cambridge: Cambridge University Press. 